\title{
EFFECT OF INNOVAR, FENTANYL AND DROPERIDOL ON THE CEREBROSPINAL FLUID PRESSURE IN NEUROSURGICAL PATIENTS
}

\author{
Raymond Miller, Henky C. Tausk, and David C.C. Stark
}

FentanYl AND DROPFRIDOL, administered either separately or combined in a fixed ratio of 1:50 as "Innovar," have been recommended as adjuncts to local anaesthesia for a wide variety of procedures. ${ }^{1-3}$ These have included diagnostic procedures, such as cerebral angiography $y^{4,5}$ on neurosurgical patients, despite the well documented respiratory depression ${ }^{6,7}$ associated with "Innovar" and fentanyl. Whereas the effects of meperidine ${ }^{8}$ and morphine ${ }^{9}$ on the cerebrospinal fluid (c.s.f.) pressure of conscious neurosurgical patients breathing air have long been known, the effects of fentanyl have received little attention when used in these circumstances, although they have been studied extensively in normocarbic ${ }^{10}$ or hypocarbic ${ }^{11}$ anaesthetized patients. It has been assumed that small doses of "Innovar" or fentanyl had little effect on the intracranial pressure of neurosurgical patients, with or without space occupying lesions, provided that the intracranial pressure was not elevated. ${ }^{12}$ We have administered "Innovar" prior to induction of anaesthesia to patients about to undergo craniotomy, to facilitate the insertion of intra-arterial and central venous lines and to produce tranquil patients.

This study was prompted by a chance observation on a patient with established lumbar spinal drainage to control intractable raised intra-cranial pressure following a subarachnoid haemorrhage. Administration of "Innovar" resulted in a dramatic rise of c.s.f. pressure.

The purpose of this study was to investigate the effects of "Innovar", fentanyl and droperidol on the c.s.f. pressure of neurosurgical patients being prepared for craniotomy and so to evaluate the suitability of these agents for neuroradiological procedures performed without general anaesthesia.

Twenty-five adult patients about to undergo craniotomy for tumour or aneurysm were studied. Patients with clinical features suggestive of raised intracranial pressure were excluded as were those with a history of a previous craniotomy or an operation on the spine. All patients were premedicated with quinalbarbitone $100 \mathrm{mg}$ and atropine $0.4 \mathrm{mg}$ one hour preoperatively. E.C.G. leads were attached, intraarterial and intravenous lines set up and the patient turned into the left lateral position with the head and spine horizontal. An 18-gauge malleable needle was then inserted into the lumbar subdural space and connected to a water manometer, care being taken to avoid any loss of fuid. After the c.s.f. pressure had stabilized the lowest level of the oscillating column relative to the level of dural puncture was noted. The mean blood pressure was also recorded and arterial blood was withdrawn for blood gas analysis. Eleven patients (Group I) were then given $2 \mathrm{ml}$ of "Innovar" (droperidol $5 \mathrm{mg}$ and fentanyl $0.1 \mathrm{mg}$ ) intra-

The Department of Anesthesia, Mount Sinai School of Medicine, of the City University of New York and the Mount Sinai Hospital, New York, New York 10029. 
venously; ten patients (Group II) were given fentanyl $0.1 \mathrm{mg}$ intravenously. Droperidol either $5 \mathrm{mg}$ or $10 \mathrm{mg}$ was administered to the remaining 4 patients (Group III).

The c.s.f. pressure and mean blood pressure were noted at intervals of one minute for the next five minutes. Arterial blood samples were withdrawn at two minutes and at five minutes for further blood gas analysis (Astrup).

After five minutes, sodium thiopentone $200 \mathrm{mg}$ was given intravenously to all patients and after one minute the c.s.f. and mean blood pressure were noted. The spinal needle was then withdrawn and the patient returned to the supine position. Following this, 100 per cent oxygen was administered by mask and anaesthesia continued in the usual manner.

However, where these initial measurements indicated a high c.s.f. pressure and it was thought desirable to have spinal drainage available during craniotomy to assist in control of brain size, the needle was connected to a standard closed lumbar drainage system. In this instance induction and intubation were accomplished in the lateral position.

\section{Results}

Group I ("Innovar"). Of the 11 patients in this group, seven had tumours and four had cerebral aneurysms. The mean age was 55 years (range 38-76 years). The mean weight was $152 \mathrm{lb}$ (range 113-205 lb). Initially the mean c.s.f. pressure was $160 \mathrm{~mm} \mathrm{H}_{2} \mathrm{O} \pm 10.2$ (S.E.), (range 110-200 $\mathrm{mm} \mathrm{H}_{2} \mathrm{O}$ ). One minute after the administration of "Innovar" the c.s.f. pressure was increased in 10 patients to a mean of $195 \mathrm{~mm} \mathrm{H}_{2} \mathrm{O} \pm 13.6$ (S.E.), (range $130-280 \mathrm{~mm} \mathrm{H}_{2} \mathrm{O}$ ). This increase was not significant. It remained unchanged in one patient. At five minutes the c.s.f. pressure had increased in all patients, to a mean of $240 \mathrm{~mm} \mathrm{H}_{2} \mathrm{O} \pm$ 21 (S.E.), (range $150-410 \mathrm{~mm} \mathrm{H}_{2} \mathrm{O}$ ). This increase was significant $(\mathrm{P}<0.05)$.

After the administration of sodium thiopentone the c.s.f. pressure fell in all cases within one minute to a mean of $147 \mathrm{~mm} \mathrm{H}_{2} \mathrm{O}$ (range $45-250 \mathrm{~mm} \mathrm{H}_{2} \mathrm{O}$ ); in three cases the pressure fell to the initial level and in five cases actually lower than that. The initial mean blood pressure in this group was 116 torr. After five minutes there was a fall in 10 patients and a small increase in one patient to a mean of 106 torr. After sodium thiopentone the blood pressure fell in all cases to a mean of 93 torr. The initial $\mathrm{Pa}_{\mathrm{CO}_{2}}$ was 37 torr \pm 0.9 (S.E.) and was $42.6 \pm 1.3$ (S.E.) at five minutes. There was a small increase at two minutes which was not significant but the change after five minutes was significant $(P<0.01)$.

The $\mathrm{Pa}_{\mathrm{O}_{2}}$ fell in all cases. The initial mean $\mathrm{Pa}_{\mathrm{O}_{2}}$ was 70.3 torr \pm 2.2 (S.E.). There was an insignificant fall to a mean of 66.1 torr \pm 2.6 (S.E.) at two minutes and a significant fall $(P<0.05)$ to a mean of $62.1 \pm 2.7$ (S.E.) over the fiveminute period.

Group II (Fentanyl). Six patients in this group had cerebral aneurysms and four had tumours.

The mean age of the ten patients was 42 years (range $19-68$ years). The mean weight was $158 \mathrm{lb}$ (range $110-230 \mathrm{lb}$ ). The mean initial c.s.f. pressure was 158.5 $\mathrm{mm} \mathrm{H}_{2} \mathrm{O} \pm 17.8$ (S.E.). In every case the pressure increased over five minutes to 


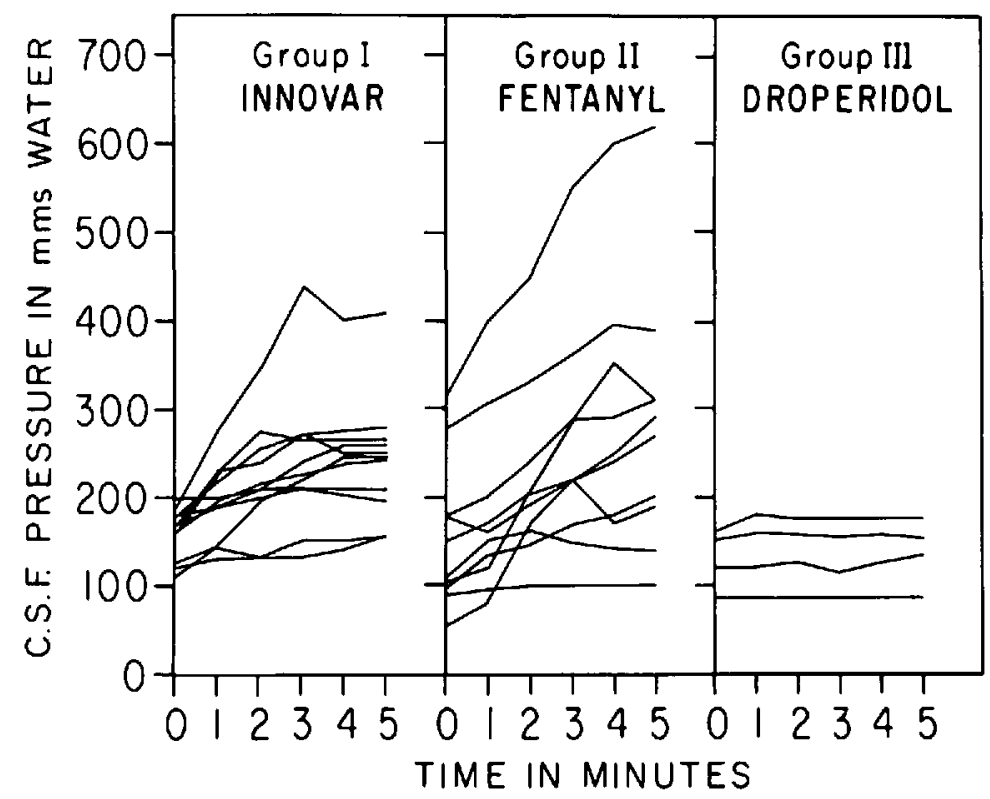

Figure 1. C.S.F. pressure changes following Innovar, fentanyl and droperidol.

a mean of $281 \mathrm{~mm} \mathrm{H}_{2} \mathrm{O} \pm 46$ S.E. $(\mathrm{P}<0.05)$. The changes at one minute were not significant.

After the administration of sodium thiopentone the mean c.s.f. pressure fell to $140 \mathrm{~mm} \mathrm{H}_{2} \mathrm{O}$ (range $40-300 \mathrm{~mm} \mathrm{H}_{2} \mathrm{O}$ ) in six patients it fell below the initial level, in one to the initial level and, in three, the final pressure was slightly higher than originally. Two patients were of particular interest in that their c.s.f. pressures were raised initially. One patient with a cerebral aneurysm had an initial pressure of $280 \mathrm{~mm} \mathrm{H_{2 }} \mathrm{O}$ which rose to $390 \mathrm{~mm} \mathrm{H}_{2} \mathrm{O}$ after five minutes and fell to $275 \mathrm{~mm} \mathrm{H} \mathrm{H}_{2} \mathrm{O}$ one minute after the administration of sodium thiopentone. The other patient had a tumour; her initial pressure was $320 \mathrm{~mm} \mathrm{H}_{2} \mathrm{O}$, which rose

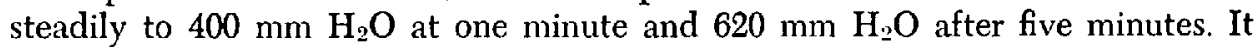
fell to $300 \mathrm{~mm} \mathrm{H.O}$ after the administration of sodium thiopentone.

The initial mean blood pressure in this group was 112 torr. Oven the fiveminute period the blood pressure fell in seven, remained unchanged in two, and rose slightly in one patient to a mean of 105 torr. After sodium thiopentone the mean blood pressure was 93.5 torr.

The initial mean $\mathrm{Pa}_{1{ }^{\circ} \mathrm{O}_{2}}$ was 33.5 torr \pm 1.4 (S.E.). This $\mathrm{Pa}_{\mathrm{CO}_{2}}$ was increased in every case at two minutes but the rise was not significant. At five minutes the mean $\mathrm{Pa}_{\mathrm{CO}_{2}}$ was 40 torr \pm 1.7 (S.E.) and this increase was significant $(\mathrm{P}<0.02)$.

In every case the $\mathrm{Pa}_{0_{2}}$ fell. The initial $\mathrm{Pa}_{\mathrm{O}_{2}}$ was 81.4 torr \pm 3.9 (S.E.) and at five minutes was significantly lower at 67.7 torr \pm 3.8 (S.E. $(\mathrm{P}<0.05$ ).

Group III (Droperidol). Of these four patients two had tumours and two had aneurysms. Droperidol was administered in doses of $5 \mathrm{mg}$ and $10 \mathrm{mg}$ to two patients each. Very little change in c.s.f. pressure, $\mathrm{Pa}_{\mathrm{O}_{2}}$ or $\mathrm{Pa}_{\mathrm{CO}}$ occurred over the five-minute period but there was a small fall in mean arterial blood pressure. 
After the administration of sodium thiopentone the c.s.f. pressure fell slightly and there was a further small fall in mean blood pressure.

Of the 21 patients to whom "Innovar" or fentanyl was administered, 11 had tumours and 10 had aneurysms. There was no significant difference between their initial mean c.s.f. pressures, but the mean c.s.f. pressure five minutes after the administration of "Innovar" or fentanyl was significantly higher in the tumour patients $(P<0.01)$.

Changes in c.s.f. pressure in the 25 patients studied are illustrated in Figure 1 and the results are summarized in Table I.

\section{Discussion}

Sophisticated methods for the measurement of cerebral blood flow and intracranial pressure ${ }^{13}$ are now available but are rarely practical or justified in a clinical setting, particularly where conscious patients are concerned. Lumbar c.s.f. pressures, though not completely reliable in reflecting intracranial pressure, ${ }^{13}$ are simple to measure and useful in interpreting the effects of anaesthetic agents and drugs provided that c.s.f. pathways are not grossly abnormal.

In the patients we have studied, increases in c.s.f. pressure occurred very rapidly after the administration of "Innovar" or fentanyl together with significant changes in arterial blood gas tensions. Large doses of fentanyl increase cerebral blood flow in the cat but both fentanyl and "Innovar" are known to decrease cerebral blood flow in dogs. ${ }^{15}$ It is usually considered, though not yet demonstrated, that these drugs reduce cerebral blood flow in man. ${ }^{11,15}$

We have assumed therefore that the increases in c.s.f. pressure which occurred in our patients were due to respiratory depression resulting in increased cerebral blood flow and increased intracranial pressure. Droperidol had little effect on the c.s.f. pressure and did not affect the $\mathrm{Pa}_{\mathrm{O}_{2}}$ or $\mathrm{Pa}_{\mathrm{CO}}$ in the four cases investigated. Since droperidol is thought to be a cerebral vasoconstrictor ${ }^{15}$ and is not associated with respiratory depression, these results were as anticipated and no further cases were studied. Our results indicate that small doses of neuroleptanalgesic agents may be associated with a rise in $\mathrm{Pa}_{\mathrm{CO}_{2}}$. This is not in agreement with the work of Barker and Jennett $(1966)^{16}$ who used neuroleptanalgesic agents during cerebral blood flow studies in patients undergoing carotid ligation and found constant $\mathrm{Pa}_{\mathrm{CO}_{2}}$ values. However, two of their eight cases showed small increases in $\mathrm{Pa}_{\mathrm{CO}_{2}}$ after an initial injection of droperidol and phenoperidine and they used fentanyl in only two cases.

C.s.f. pressures in health have recently been studied by Gilland, Tourtellotte and Henderson ${ }^{17}$ and they found levels as high as $240 \mathrm{~mm} \mathrm{H}_{2} \mathrm{O}$ in normal subjects. Previously pressures above $200 \mathrm{~mm} \mathrm{H} \mathrm{H}_{2} \mathrm{O}$ were considered definitely abnormal. Seven of our cases, receiving "Innovar" or fentanyl, with an initial c.s.f. pressure within the normal range, finally had pressures greater than $250 \mathrm{~mm} \mathrm{H}_{2} \mathrm{O}$. Small sedative doses of barbituates are not considered to affect intracranial pressure significantly whereas anaesthetic doses reduce intracranial pressure in the absence of respiratory depression. ${ }^{18}$ Our results confirm the fall in intracranial pressure after anaesthetic doses of sodium thiopentone but this would seem to 


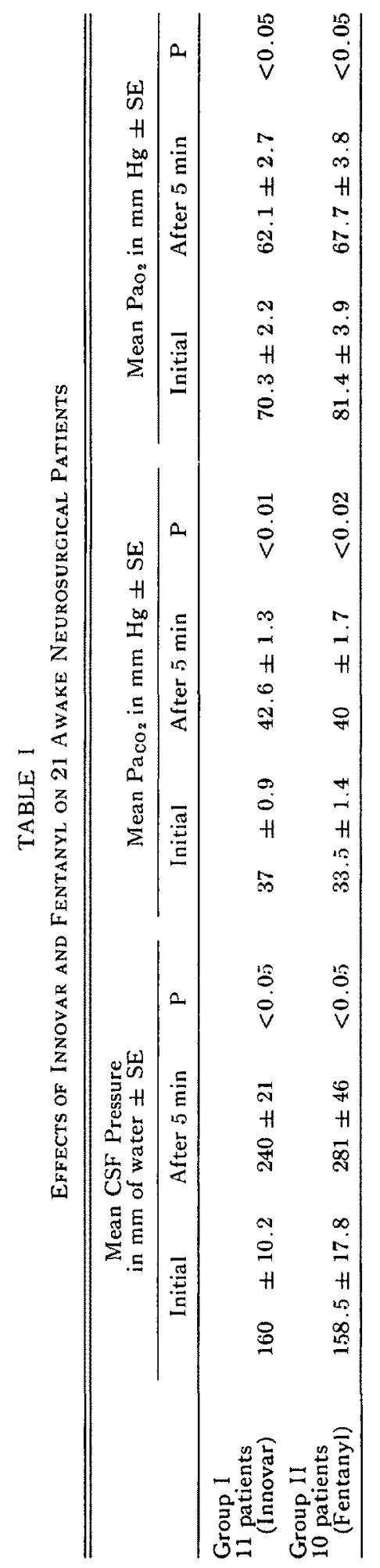


occur even if slight respiratory depression is present since it occurred in all our patients.

\section{Conclusions}

Neuroleptanalgesic agents may lead to respiratory depression and significant increases in intracranial pressure even when small doses are used.

These agents should be used with caution in neurosurgical patients with intracranial lesions undergoing angiography or pneumoencephalography without general anaesthesia. In the presence of a raised intracranial pressure neuroleptanalgesic agents should not be used for premedication or as an adjunct to local anaesthesia.

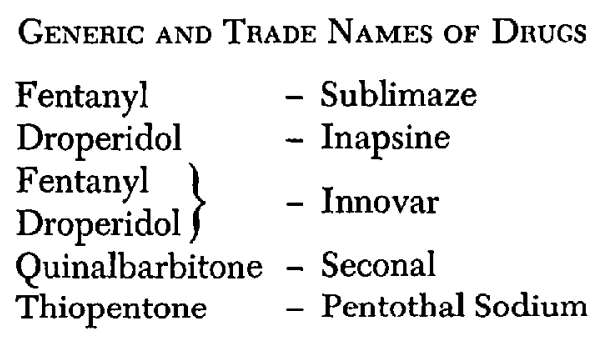

\section{RÉSUMÉ}

On a effectué chez des patients de neurochirurgie des mesures du liquide céphalo-rachidien (L.R.C.) avant et après l'administration d'inovar, dropéridol et fentanyl. Les patients avaient reçu une prémédication légère. Le dropéridol n'affecte pas la dynamique du L.R.C. Les changements observés étaient associés dans le temps avec des changements significatifs de $\mathrm{Pa}_{2}$ et $\mathrm{Pa}_{\mathrm{CO}_{2}}$, indiquant une dépression respiratoire. Ces résultats doivent nous rappeler les dangers liés à une depression respiratoire chez des patients avec des pressions anormales du L.C.R. Ceci s'applique en particulier aux patients soumis à des études neuroradiologiques. Chez ces malades, de telles augmentations pourraient influencer l'état neurologique. De plus, l'augmentation de la $\mathrm{Pa}_{\mathrm{CO}_{2}}$ pourrait modifier le flot sanguin régional et rendre l'interprétation radiologique plus difficile. On oublie malheureusement fréquemment que l'innovar est un mélange de médicaments et l'on ne se préoccupe pas suffisamment de la dépression respiratoire causée par le fentanyl. Si une sédation est requise durant ces procédures, notre étude suggère que le dropéridol seul ne produit pas de modifications importantes.

\section{REFERENCES}

1. Folpes, F.F. Neuroleptanalgesia for awake intubation and peroral endoscopies. Int. Anesthesiology Clinics. Boston, Little, Brown and Company 11: No. 3, 93-102 (1973).

2. Graham, T.P., Atwood, G.F., \& Werner, B. Use of droperidol-fentanyl sedation for cardiac catheterization in children. Am. Heart J. 87: 287-293 (1974).

3. Grizzard, H.T., Wiltcher, J., North, W.C., \& Hiatt, R.L. The usefulness of Innovar as an adjunct to local anesthesia in ocular surgery. Southern Med. J. 62: 785-789 (1969).

4. Jackson, F.E., Elrer, T., Crosson, R., \& Holden, D.A. The utilization of Innovar 
neuroleptanalgesia for subtraction cerebral angiography. Diseases of the Nervous System 34: $341-345$ (1973).

5. Jackson, F.E., Fleming, P.M., Wilcox, J.R., \& Barbarick, D.L. Neuroleptanalgesia for carotid angiography in neurosurgical patients. Military Medicine 138; 92-95 (1973).

6. Bechtoldt, A.A. \& Murray, W.J. Innovar-induced respiratory depression. Anesth. Analg. $47: 395-398$ (1968)

7. Foldes, F.F., Kepes, E.R., Kronfeld, P.P., \& Shiffman, H.P. A rational approach to neuroleptanesthesia. Anesth. Analg. 45: 642-652 (1966).

8. KEPES, E.R. Effect of Demerol on the cerebrospinal fluid pressure. Anesthesiology 13: 281-286 (1952).

9. Keats, A.S. \& Mrthoefer, J.C. The mechanism of increased intracranial pressure induced by morphine. New Engl. J, Med. 252: 1110-1113 (1955).

10. Sari, A., OKUdA, Y., \& TAKeshita, H. The effects of Thalamonal on cerebral circulation and oxygen consumption in man. Brit. J. Anaesth. 44: 330-334 (1972).

11. Fitch, W., Barker, J., Jennett, W.B., \& McDowall, D.G. The influence of neuroleptanalgesic drugs on cerebrospinal fluid pressure. Brit. J. Anaesth. 41: 800-806 (1969).

12. Smrth, A.L. \& Wollman, H. Cerebral blood flow and metabolism: effects of anesthetic drugs and techniques. Anesthesiology 36:378-400 (1972).

13. LangFitT, T.W. Summary of first international symposium on intracranial pressure. J. Neurosurg. 38: 541-544 (1973).

14. Freeman, J. \& Ingvar, D.H. Effects of fentanyl on cerebral cortical blood flow and EEG in the cat. Acta Anaesth. Scand. 11: 381-391 (1967).

15. Michenfelder, J.D. \& Treye, R.A. Effects of fentanyl, droperidol and Innovar on canine cerebral metabolism and blood flow. Brit. J. Anaesth. 43: 630-635 (1971).

16. Barker, J. \& JENNET, W.B. Neuroleptanalgesia for cerebral blood flow studies in patients undergoing carotid ligation. Acta Anaesth. Scand. suppl. 24: 47-50 (1966).

17. Gilland, O., Tourtellotte, W.W., O'Tauma, L., \& Henderson, W.G. Normal cerebrospinal fluid pressure. J. Neurosurg. 40: 587-593 (1974).

18. SONDERGARD, W. Intracranial pressure during general anesthesia. Dan. Med. Bull. 8: 18$25(1961)$. 